Article

\title{
Effect of Post-Cure on the Static and Viscoelastic Properties of a Polyester Resin
}

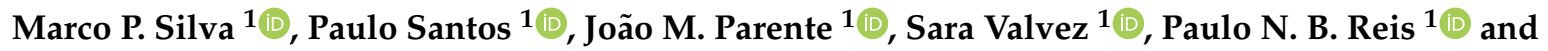 \\ Ana P. Piedade $2, * \mathbb{D}$ \\ 1 C-MAST, Department of Electromechanical Engineering, University of Beira Interior, Calçada Fonte do \\ Lameiro, 6201-100 Covilha, Portugal; marco.silva@ubi.pt (M.P.S.); paulo.sergio.santos@ubi.pt (P.S.); \\ joao.miguel.parente@ubi.pt (J.M.P.); sara.valvez@ubi.pt (S.V.); preis@ubi.pt (P.N.B.R.) \\ 2 University of Coimbra, CEMMPRE, Department of Mechanical Engineering, 3030-788 Coimbra, Portugal \\ * Correspondence: ana.piedade@dem.uc.pt; Tel.: +351-23-979-0700
}

Received: 22 July 2020; Accepted: 24 August 2020; Published: 26 August 2020

\begin{abstract}
This work intends to study the effect of the curing parameters on the mechanical properties of a polyester resin without a complete curing reaction process. For this purpose, cures at room temperature, $40^{\circ} \mathrm{C}$, and $60^{\circ} \mathrm{C}$, and post-cures at $40^{\circ} \mathrm{C}$ and $60^{\circ} \mathrm{C}$, with different exposure times, were considered. Three-point bending tests were performed to assess the bending properties and both stress relaxation and creep behavior. The degree of crosslinking was estimated by evaluating the $C=C$ ester bond, by Fourier infrared spectroscopy and complemented with the thermal characterization made by differential scanning calorimetry. The results showed that higher curing temperatures are preferable to methods involving curing and post-curing, which can be confirmed by the higher degree of conversion of unsaturated ester bonds at $60^{\circ} \mathrm{C}$. Compared to the resin cured at room temperature, the bending strength increased by $36.5 \%$ at $40{ }^{\circ} \mathrm{C}$ and $88.6 \%$ at $60{ }^{\circ} \mathrm{C}$. A similar effect was observed for bending stiffness. In terms of stress relaxation and creep strain, the lowest values were obtained for samples cured at $60^{\circ} \mathrm{C}$.
\end{abstract}

Keywords: polyester resin; post-cure; mechanical properties; mechanical testing

\section{Introduction}

Thermosetting resins are extensively used in diverse areas ranging from boats, consumer goods, aircraft, automotive components, and several industrial applications. Regarding the polyester resins, for example, they are the most widely used resins in polymer matrix composites, particularly in the maritime and automotive industries, and represent about $75 \%$ of total resin used in the composites industry. They are the most economical resin systems used in engineering applications that, simultaneously, combine low viscosity, adequate resistance to water and variety of chemicals, adequate resistance to weathering and ageing, good wetting to glass fibers, and relatively low shrinkage between 4 and $8 \%$ during curing. Nerveless, polyester resins have limited use in high-performance composites [1-3].

Regardless of their excellent aptitude for different manufacturing processes, such as compression molding, injection molding, resin transfer molding, and hand lay-up process [1,2], the main problem is related to their curing process [4-6]. The complexity of the problem is considerable, mainly in the quality control of the cure, because the process is affected by numerous factors, including ambient temperature, quality, and quantity of catalysts, the volume of the cured portion, and heat removal from the curing area. Therefore, both mechanical performance and surface appearance will be dramatically affected by the quality of the cure, a problem that is transversal to the various types of thermosetting resins $[7,8]$. 
The curing process of unsaturated polyester is exothermic due to a polymerization reaction that causes crosslinking among individual linear polymer chains [9-12]. Therefore, as polymerization by free radicals, the curing reaction of unsaturated polyester can be initiated by either the thermal or reduction-oxidation (redox) initiation system. Moreover, organic peroxides (initiators) can also initiate the reaction by adding metallic salts or amines (initiator + promoter system) at room temperature (RT). Unlike other thermosetting resins, no byproducts are formed during the curing reaction, and these resins can be molded, cast, and laminated at low pressures and temperatures [13-16]. However, many of the processing problems arise precisely in this curing process, which are generally ignored in the production planning phase. In this context, it is essential to have the curing data to correctly understand the final properties of polymers and/or composites and, thus, to ensure safe applications.

According to the open literature, different parameters define the post-cure process, but the post-cure temperature is considered the most important factor that influences the extent of crosslinking [8]. Senthilkumar et al. [17], for example, developed works about the temperature effect on the mechanical properties of sisal fiber reinforced polyester composites. For this purpose, composites were produced for different curing temperatures ranging from 60 to $100{ }^{\circ} \mathrm{C}$ in steps of 10 with a hot compression molding process. The best tensile and impact strength was obtained for composites cured at $100{ }^{\circ} \mathrm{C}$. Kumar et al. [18] studied the post-curing temperature and time on the interlaminar shear strength (ILSS) and glass transition temperature ( $\mathrm{T}_{\mathrm{g}}$ ) of glass fiber reinforced polymer (GFRP) composites. Three different temperatures $\left(80^{\circ} \mathrm{C}, 110^{\circ} \mathrm{C}\right.$, and $\left.140{ }^{\circ} \mathrm{C}\right)$ and four different periods $(2 \mathrm{~h}, 4 \mathrm{~h}, 6 \mathrm{~h}, 8 \mathrm{~h}$, and $12 \mathrm{~h}$ ) were analyzed. They concluded that post-curing at $140{ }^{\circ} \mathrm{C}$ for $6 \mathrm{~h}$ gave better thermal and mechanical properties as compared to post-curing at different temperatures and periods. For example, in terms of ILSS, a drastic increase was observed between 2 and $6 \mathrm{~h}$, but, when the maximum was reached after $6 \mathrm{~h}$, this property remains constant (a negligible effect was observed). According to the authors, the energy available at lower post-curing temperatures may not be enough to enhance further the wettability at the fiber/matrix interface.

In contrast, on the highest temperature, the energy received by the system is reasonably high for activating the monomers to crosslink further. Campana et al. [19] studied the effect of post-cure on flax fiber reinforced epoxy composites, and the following conditions were analyzed: composite cured at $80^{\circ} \mathrm{C}$ for $24 \mathrm{~h}, 2 \mathrm{~h}$ at $100{ }^{\circ} \mathrm{C}, 120^{\circ} \mathrm{C}$, and $150{ }^{\circ} \mathrm{C}$. They observed a crosslinking degree of $92 \%$ and a $\mathrm{T}_{\mathrm{g}}$ of $121^{\circ} \mathrm{C}$ for $24 \mathrm{~h}$ of curing at $80^{\circ} \mathrm{C}$. Nevertheless, when the resin was post-cured $2 \mathrm{~h}$ at $150{ }^{\circ} \mathrm{C}$, these values increased to $100 \%$ and $165^{\circ} \mathrm{C}$, respectively. This trend was expected because the goal of post-cure is to achieve a crosslinking rate of $100 \%$. After post-cure, the molecular mobility within the resin is reduced, leading to a higher $\mathrm{T}_{\mathrm{g}}$. It was also noticed that the resin and composite followed the same trend, but, while the $\mathrm{T}_{\mathrm{g}}$ of the composite was lower when cured at $80^{\circ} \mathrm{C}$ for $24 \mathrm{~h}$, all conditions that involved post-cured promoted higher values. This behavior is explained by a change in specific heat or thermal conductivity when the fibers were introduced [20,21]. Finally, Elleuch et al. [22] confirmed that a woven glass-polyester composite's mechanical properties increased with the post-cure. The low crosslinking density effect increases the resin ductility and the failure strain. Therefore, a rigid interface (brittle failure) was obtained in the case of post-cure and a weak interface (progressive failure) in the case of post-cure absence.

Therefore, the main goal of the present work is to study the curing parameters of a polyester resin usually used on surf boards to understand their effects on mechanical properties. Moreover, due to some degree of ductility required for the specific application of this polyester resin, the curing and post-curing processes are recommended, by the manufacturer, to occur at much lower temperatures than the ones usually reported in the literature. Therefore, special attention will be given to the viscoelastic behavior of the resin because, due to its inherent viscoelasticity, composites will be prone to creep and stress relaxation, constituting a significant challenge when used in long-term applications. 


\section{Materials and Methods}

A polyester resin (AROPOL FS 1962, SF Composites, Mauguio, France) was mixed with 1\% peroxide (MEKP-50, SF Composites, Mauguio, France), and, after mixing, the system was degassed in a vacuum oven to remove any potential air bubbles. According to the manufacture, the resin presents low reactivity, which implies that after curing is almost inert towards other chemical species, and it is formulated with additives: a preaccelerating compound (enabling faster polymerization), and an UV stabilizer. The main properties/characteristics are (at RT): a viscosity of $550 \mathrm{mPa} . \mathrm{s}$, a styrene content of $34 \%$, and a geltime with $1.5 \%$ of MEKP-50 of 12 minutes. The crosslinking agent (or hardener) is a methyl ethyl ketone peroxide (MEKP-50) 33\% (v/v) in dimethyl phthalate with a viscosity of $20 \mathrm{mPa} . \mathrm{s}$, a peroxide content of $33 \%$, and active oxygen content between 8.8 and $9 \%$. After being degassed, the mixture was poured into a rectangular cardboard mold, with dimensions of $100 \times 100 \times 3 \mathrm{~mm}^{3}$, and between acetate sheets to both facilitate its removal after curing and obtaining an excellent surface finish. After unmolding the plates, they were submitted to different post-cures that are summarized in Table 1. Different temperatures were considered based on the supplier's datasheet and the post-cure time based on the different values suggested in the literature $[18,19]$. Finally, the specimens were cut from those plates, with the final dimensions of $100 \times 10 \times 3 \mathrm{~mm}^{3}$, using a diamond saw and a moving speed chosen to reduce the heat in the specimen (Figure 1).

The analysis of the chemical functional groups of the resin, crosslinker, and cured samples was performed using Fourier transform infrared spectroscopy (FTIR) in the reflectance mode, using the non-destructive attenuated total reflectance (ATR) sampling technique.

The infrared spectrum $\left(4000-550 \mathrm{~cm}^{-1}\right)$ of the samples at room temperature was recorded using a Perkin Elmer Frontier spectrometer (FT NIR/MIR, PerkinElmer, Waltham, MA, USA), equipped with an FR-DTGS detector and a KBr beam splitter. Spectrum registration was performed with a $4.0 \mathrm{~cm}^{-1}$ resolution with 16 accumulations. A Perkin Elmer sampling accessory, universal ATR module (UATR universal attenuated total reflectance, PerkinElmer, Waltham, MA, USA) with diamond crystal/ZnSe, was used, and a constant $80 \mathrm{~N}$ force was applied throughout the spectrum register. The specimens were analyzed without any treatment and three repetitions of each specimen were performed to access the homogeneity of the prepared samples. For the analysis of the chemical functional groups of interest, a deconvolution was made in the original spectra through Origin ${ }^{\circledR}$ software (version 6.1, OriginLab, Northampton, MA, USA). Due to the use of the same force all spectra were normalized and the area of specific bands used for the determination of the degree of conversion of the double bonds.

Table 1. Summary of cure and post-cure conditions.

\begin{tabular}{ccccc}
\hline \multirow{2}{*}{ Cure Method } & \multicolumn{2}{c}{ Cure } & \multicolumn{2}{c}{ Post-Cure } \\
\cline { 2 - 5 } & Time (h) & Temperature $\left({ }^{\circ} \mathbf{C}\right)$ & Time (h) & Temperature $\left({ }^{\circ} \mathbf{C}\right)$ \\
\hline 1 & 360 & RT & - & - \\
2 & 24 & RT & 3 & 40 \\
3 & 24 & RT & 6 & 40 \\
4 & 24 & RT & 12 & 40 \\
5 & 24 & RT & 24 & 40 \\
6 & 24 & 40 & - & - \\
7 & 24 & RT & 3 & 60 \\
8 & 24 & RT & 6 & 60 \\
9 & 24 & RT & 12 & 60 \\
10 & 24 & RT & 24 & - \\
11 & 24 & 60 & - & \\
\hline
\end{tabular}

$\mathrm{RT}=$ Room temperature. 


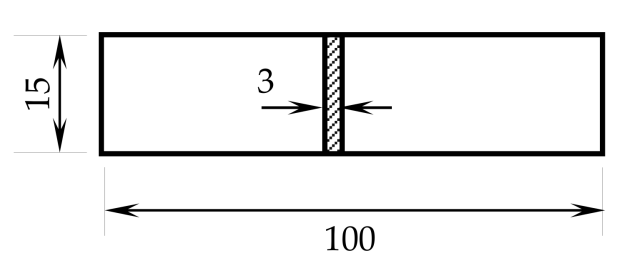

(a)

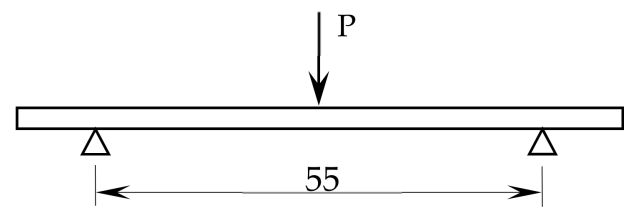

(b)

Figure 1. (a) Specimens geometry (dimensions in $\mathrm{mm}$ ) and (b) schematic view of the three-point bending apparatus. All dimensions in $\mathrm{mm}$.

The thermal events of the specimens, especially $\mathrm{T}_{\mathrm{g}}$, were determined by differential scanning calorimetry (DSC, TA Instruments, Newcastle, USA) in a DSC Q100 V9.9 equipment, with a heating rate of $10^{\circ} \mathrm{C} \cdot \mathrm{min}^{-1}$ and with a constant nitrogen flow of $50 \mathrm{~mL} \cdot \mathrm{min}^{-1}$. The $\mathrm{T}_{\mathrm{g}}$ values were determined through the maximal height of the 1st derivative of each obtained curve.

Three-point bending (3PB) static tests were performed with the spam of $40 \mathrm{~mm}$, according to ASTM Standard D 7264/D 7264M-07 [23], and a Shimadzu AG-10 universal testing machine (Shimadzu Corp., Kyoto, Japan) equipped with a $10 \mathrm{kN}$ load cell was used. For each condition, at least five specimens were tested at room temperature and a rate of $2 \mathrm{~mm} \cdot \mathrm{min}^{-1}$.

The flexural properties were also obtained according to ASTM Standard D 7264/D 7264M-07 [23] and, for example, while the flexural strength was calculated as the nominal stress at the middle span section, using the maximum value of the load Equation (1), the bending stiffness modulus was obtained by linear regression of the load-displacement curves considering the interval in the linear segment and according to Equation (2). A correlation factor more significant than $95 \%$ was used. Finally, the flexural strain $(\varepsilon)$ was calculated according to Equation (3).

$$
\begin{gathered}
\sigma=\frac{3 P L}{2 b h^{2}} \\
E=\frac{\Delta P \cdot L^{3}}{48 \Delta u \cdot I} \\
\varepsilon_{f}=\frac{6 \times S \times h}{L^{2}}
\end{gathered}
$$

where $P$ is the load, $S$ the deflexion, $L$ the span length, $b$ the width, $h$ the thickness of the specimen, $I$ the moment of inertia of the cross-section and $\Delta P$ as well as $\Delta u$, respectively, the load range and flexural displacement range in the middle span for an interval in the linear region of the load versus displacement plot.

The same equipment (Shimadzu AG-10) was used to carry out stress relaxation (SR) and creep tests at room temperature and with similar specimens to those shown in Figure 1. In the first case, all experimental procedure was supported by ASTM D6048-07 [24], where a fixed strain was applied (correspondent to around $51.5 \mathrm{MPa}$ for all configurations) and the stress recorded during the loading time of $10,800 \mathrm{~s}$. For this study, only specimens cured at room temperature (method 1 ) and with post-cure at $40^{\circ} \mathrm{C}$ for $24 \mathrm{~h}$ (method 5) and $60^{\circ} \mathrm{C}$ for $24 \mathrm{~h}(\operatorname{method} 6)$ were analyzed. Finally, this bending strain value was selected to guarantee that all SR tests were carried out in the elastic regime of all conditions studied. The creep tests were carried out according to the procedures described in ASTM D7337M-12 [25], at room temperature, for constant stress of $20 \mathrm{MPa}$, and the displacement recorded during the loading time. In both cases, the data were analyzed according to the respective ASTM standards. On the other hand, and as reported in the open literature [26-28], these short-term tests reveal to be an easy, fast, and reliable method to predict long-term behavior. In fact, due to the main costs incurred with long-term test programs, in addition to the fact that long periods between the development of new or improved materials and their applications are not allowed, it is highly desirable that the design data could be obtained by extrapolating the results obtained by short-term tests. 


\section{Results and Discussion}

An analysis of the chemical modifications was carried out, considering the different curing parameters. Figure 2 shows the FTIR spectra of the polyester resin, crosslinker agent (CL), and curing process at room temperature (method 1). Only the absorptions bands of the stretching mode of carbonyl groups $(>\mathrm{C}=\mathrm{O})$ at $1720 \mathrm{~cm}^{-1}$, and the polyester $\mathrm{C}=\mathrm{C}$ bonds $\left(982 \mathrm{~cm}^{-1}\right)$, as assigned by other researchers [12,29-31], will be considered.

The normalized ratio of the absorption between the mentioned peaks, taking the peak of the carbonyl group as an internal reference, after curing (Figure 3), allows estimating the degree of conversion of the $\mathrm{C}=\mathrm{C}$ from polyester bonds $(X)$, according to previous studies [32]. The results are displayed in Figure 4 and can provide a rough approximation of the conversion of double bonds. However, it must be highlighted that the covalent bond between adjacent macromolecules can occur via other chemical reactions that do not involve the polyester unsaturated $\mathrm{C}=\mathrm{C}$ bonds.

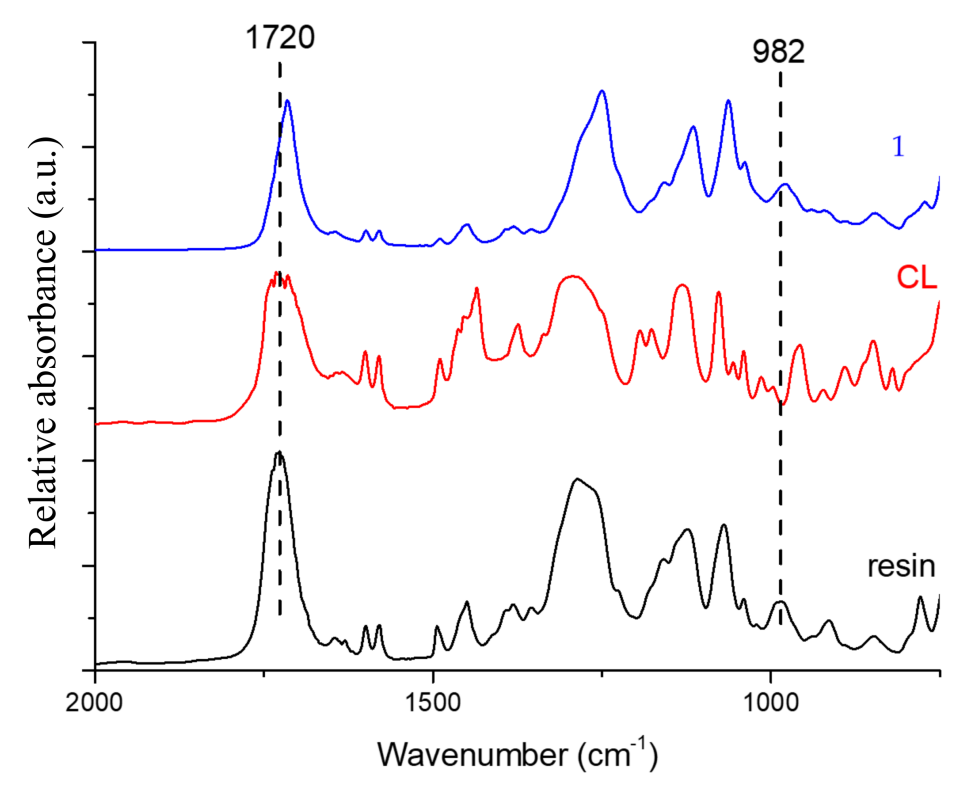

Figure 2. FTIR spectra of the resin, crosslinker (CL) and sample subjected to curing parameter 1.

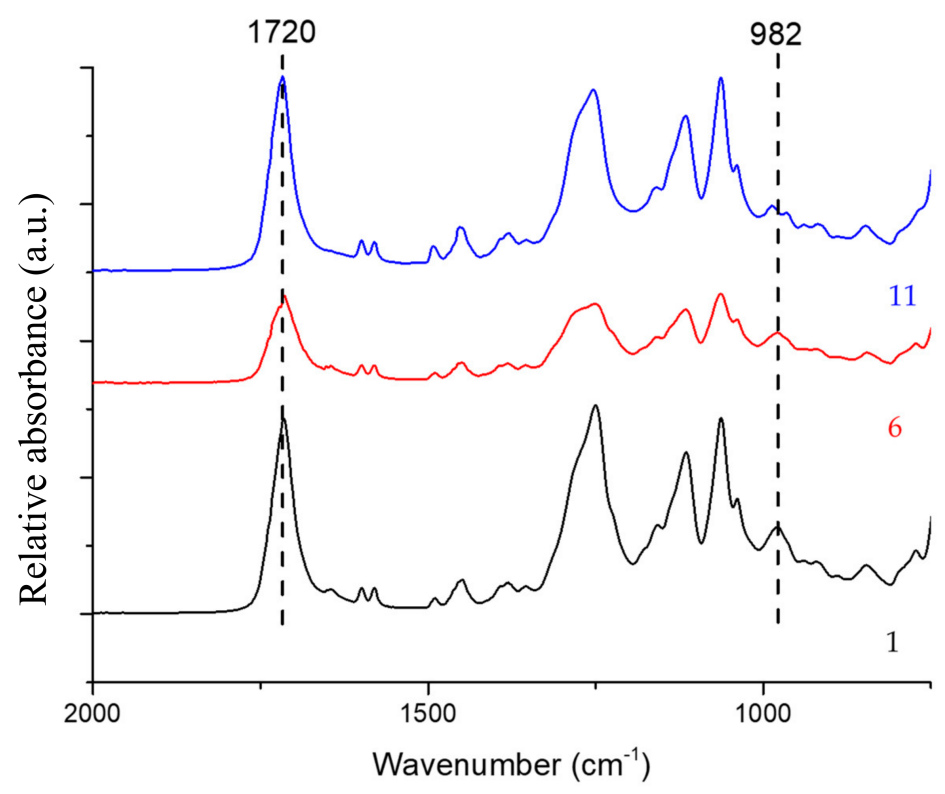

Figure 3. FTIR spectra of samples cured according to parameters 1, 6, and 11 . 
It is possible to conclude that a higher degree of conversion was obtained when a higher temperature was used at the beginning of the curing process, as suggested by the comparison between the values from methods 1,6 , and 11 . The use of the first step of $24 \mathrm{~h}$ curing at room temperature followed by different curing times at higher temperatures (specimens $2-5$ and 7-10), induced an almost linear increase of the degree of conversion. These results suggest that the RT induced an increase of the mixture viscosity that makes the evolution of further crosslinking in the post-curing stage difficult. The results suggest that to obtain a higher degree of conversion of the double bonds it is preferable to start with a higher temperature of the curing reaction, instead of a lower temperature followed by higher temperatures in the post-curing step.

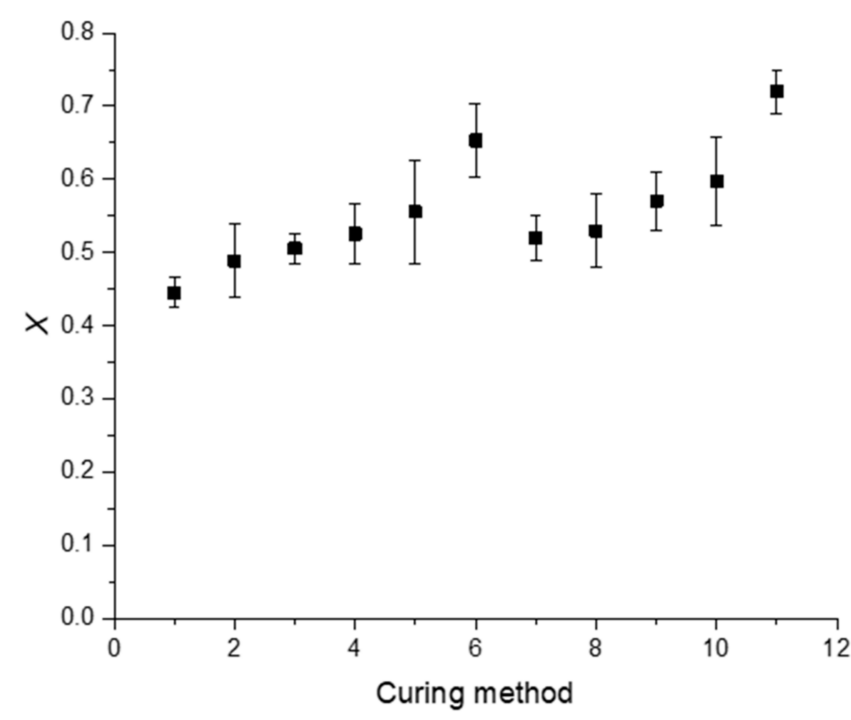

Figure 4. Degree of conversion of $C=C$ polyester bonds $(X)$ according to the curing parameters.

In the literature, at least for the last three decades, DSC studies are used to more accurately calculate the percentage of the crosslinking degree [33-36]. However, the reported studies usually refer to the system with a complete crosslinking reaction, which, as stated before, will not occur for the used resin nor for the tested temperatures. Nevertheless, in this work the DSC values provided additional information through the $\mathrm{T}_{\mathrm{g}}$ determination (Table 2 and Figure 5).

Table 2. Average and standard deviation values of $\mathrm{T}_{\mathrm{g}}$ calculated from differential scanning calorimetry (DSC).

\begin{tabular}{cccc}
\hline \multirow{2}{*}{ Curing Parameters } & \multicolumn{3}{c}{$\mathbf{T}_{\mathbf{g}}$ Values $\left({ }^{\circ} \mathbf{C}\right)$} \\
\cline { 2 - 4 } & $\mathbf{T}_{\mathbf{g} \mathbf{1}}$ & $\mathbf{T}_{\mathbf{g} \mathbf{2}}$ & $\mathbf{T}_{\mathbf{g} \mathbf{3}}$ \\
\hline 1 & $19.5 \pm 0.8$ & $66.8 \pm 0.2$ & n.d. \\
2 & $18.7 \pm 1.5$ & $66.4 \pm 0.3$ & n.d. \\
3 & $18.0 \pm 0.7$ & $66.6 \pm 0.6$ & n.d. \\
4 & $17.7 \pm 1.0$ & $55.8 \pm 0.2$ & n.d. \\
5 & $17.8 \pm 1.0$ & $63.5 \pm 0.3$ & $143.7 \pm 2.0$ \\
6 & n.d. & $62.6 \pm 0.3$ & $159.1 \pm 0.1$ \\
7 & n.d. & $62.1 \pm 0.5$ & $162.0 \pm 1.0$ \\
8 & n.d. & $58.3 \pm 0.9$ & $162.8 \pm 0.7$ \\
9 & n.d. & $62.3 \pm 0.3$ & $163.3 \pm 0.3$ \\
10 & n.d. & $62.5 \pm 1.0$ & $165.2 \pm 0.8$ \\
11 & n.d. & $62.1 \pm 0.0$ & $157.4 \pm 0.2$ \\
\hline
\end{tabular}

n.d. $=$ not detected. 
The results indicate that when the curing process was made at room temperature, a $\mathrm{T}_{\mathrm{g} 1}$ around $16{ }^{\circ} \mathrm{C}$ always appeared. This indicates that the system presents free styrene molecules that are not crosslinked. They contribute to a high free volume of the system [33], which, consequently, presents a low $\left(\mathrm{T}_{\mathrm{g} 1}\right)$. Even with a post-cure step at $40^{\circ} \mathrm{C}$ (specimens $\left.2-5\right)$ this endothermal transition occurred. For higher times of post-curing at $40{ }^{\circ} \mathrm{C}$ the system began to present a $\mathrm{T}_{\mathrm{g}}$ value, around $144{ }^{\circ} \mathrm{C}\left(\mathrm{T}_{\mathrm{g} 3}\right)$, which is the main indicator of the crosslinking reaction. This first $\mathrm{T}_{\mathrm{g}}$ disappeared when the curing process was made at 40 or $60^{\circ} \mathrm{C}$ with or without subsequently post-curing (specimens $6-11$ ) indicating the low crosslinking efficiency of the process when the curing step was made at room temperatures. These results reinforce the observations made after the FTIR characterization and, according to the literature the process is limited by the decrease of the diffusion of the reactive species, because radicals are trapped and the propagation reaction is stopped [36]. For the system that begins with the curing temperature of $60^{\circ} \mathrm{C}$ the post-cure procedure has very little effect on the crosslinking percentage, as the $\mathrm{T}_{\mathrm{g} 3}$ increased for $0 \mathrm{~h}$ or $24 \mathrm{~h}$ of post-curing, at RT, was not significant.

Flexural static tests were performed to obtain the bending properties against the different cure procedures (different exposure times and temperatures). In this context, Figure 6 presents typical bending stress versus strain curves obtained for each condition, which are representative of all other methods.

Even though Figure 6a represents the results obtained for curing parameters 4 (post-curing at $40{ }^{\circ} \mathrm{C}$ for $12 \mathrm{~h}$ ), it is representative of all the specimens that involved the curing temperature of $40{ }^{\circ} \mathrm{C}$. In this case, (Figure 6a) all curves present two distinct regions: a linear behavior up to around $4-5 \%$ of the bending strain, followed by a non-linear region in which the maximum bending stress occurs. These two regions appeared in all samples cured or post-cured at $40{ }^{\circ} \mathrm{C}$, where the strain corresponding to the maximum bending stress occurred between $2 \%$ and $4 \%$. However, the bending failure strain reached values above $10 \%$ due to the low crosslinking density $[19,22]$. According to Figure 4, the complete crosslinking has not yet been reached and, consequently, a certain level of molecular mobility is expected.

On the other hand, for specimens where the curing temperature of $60^{\circ} \mathrm{C}$ was involved, all curves show a nearly fragile behavior. In these conditions, a linear region up to the maximum load was observed, followed by a significant drop, due to reduced molecular mobility promoted by the high density of crosslinking [19,22]. As reported in Figure 4 and Table 2, and comparatively to the value obtained at room temperature, the degree of conversion was around 1.4 times higher for $40{ }^{\circ} \mathrm{C}$ and 1.6 times higher for $60^{\circ} \mathrm{C}$. Therefore, a higher degree of conversion was obtained for higher temperatures and, in this case, the bending failure strain coincided with the maximum bending stress, typical behavior of a brittle material.

Figure 7 presents the maximum bending stress against the curing parameters in terms of average values (marks), and the dispersion bands indicate the maximum and minimum values for each condition. It is possible to observe that the curing parameters had a significant influence on the maximum flexural strength of the polyester resin.

From Figure $7 \mathrm{a}$, for example, it is noticed that the use of higher temperatures in the curing process, and without post-cure (specimens 6 and 11), was responsible for higher bending strengths. Compared to the resin cured at room temperature (specimen 1), the bending strength increased around $36.5 \%$ for $40{ }^{\circ} \mathrm{C}$ (specimen 6) and $88.6 \%$ for $60^{\circ} \mathrm{C}$ (specimen 11) due to the higher degree of conversion of unsaturated $\mathrm{C}=\mathrm{C}$ bonds. Therefore, the lower molecular mobility, promoted by the higher conversion of double bonds, is responsible for the higher bending strengths $[19,22]$. 

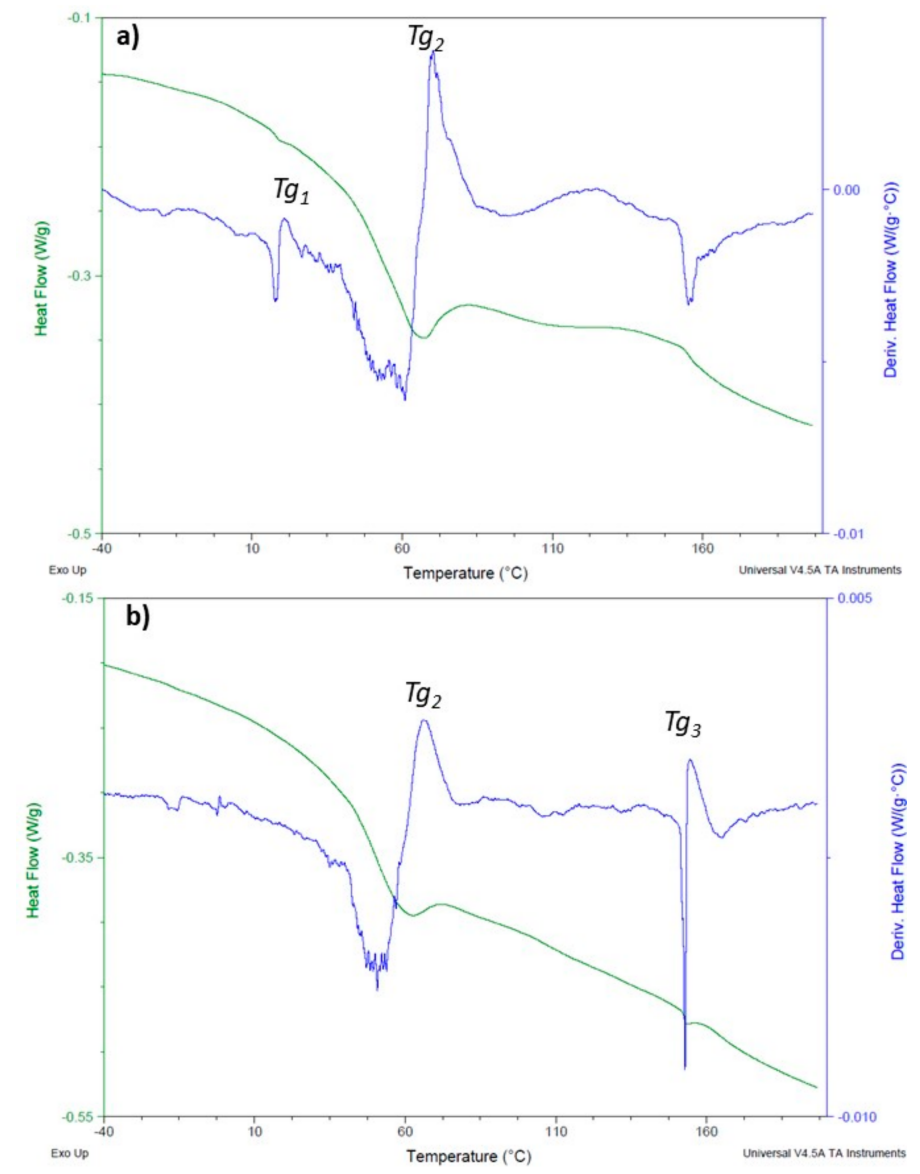

Figure 5. DSC heat flows and derivatives of specimens 1 (a) and $11(\mathbf{b})$, showing the $\mathrm{T}_{\mathrm{g}}$ values determination.
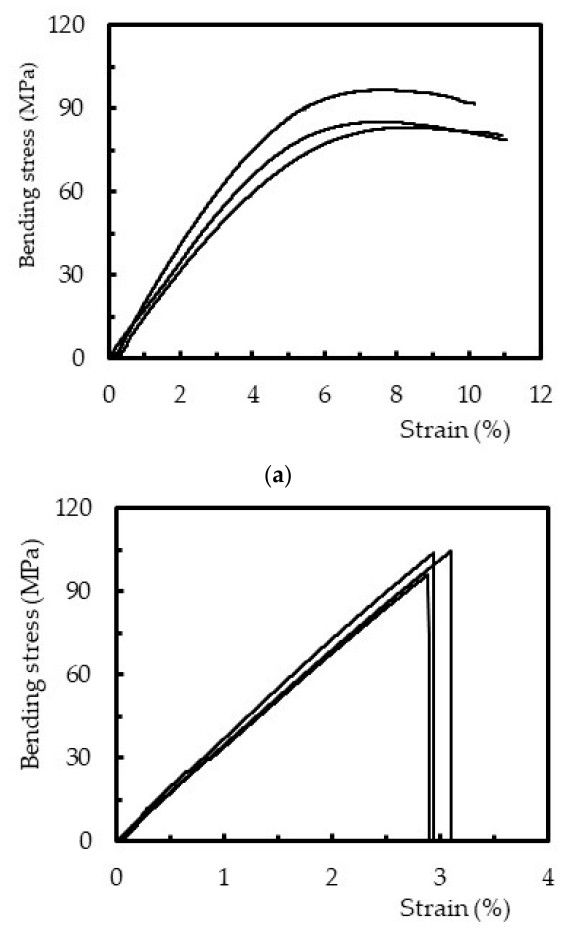

(b)

Figure 6. Flexural stress versus strain for: (a) post-cure at $40{ }^{\circ} \mathrm{C}$ for $12 \mathrm{~h}$ (specimen 4 ) and (b) post-cure at $60{ }^{\circ} \mathrm{C}$ for $6 \mathrm{~h}$ (specimen 8 ). 


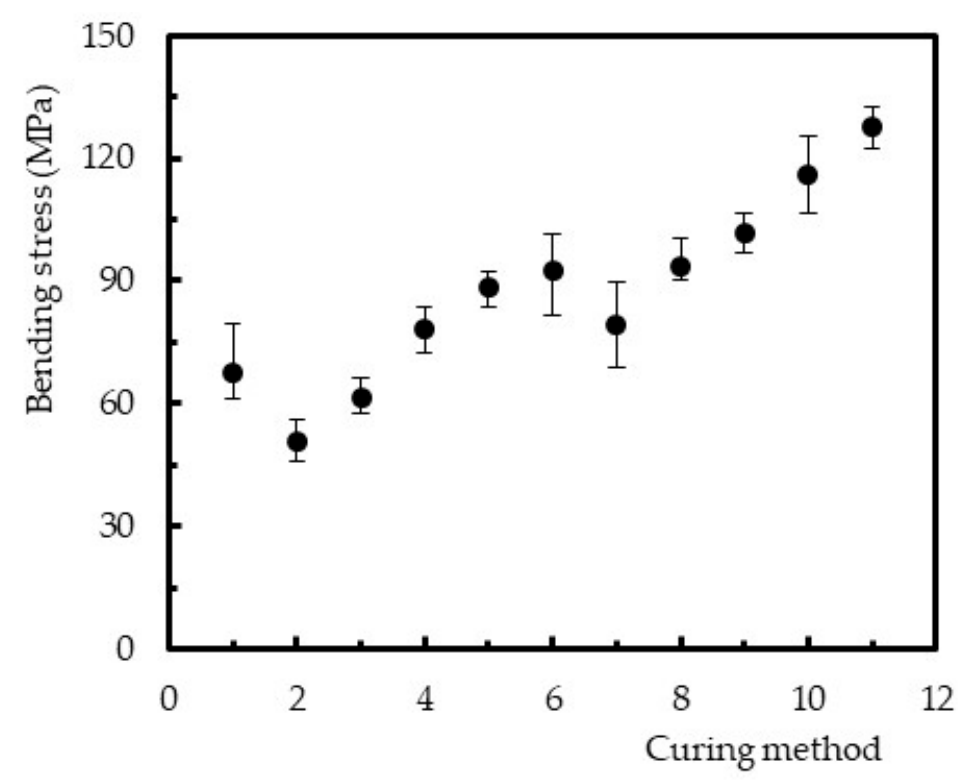

(a)

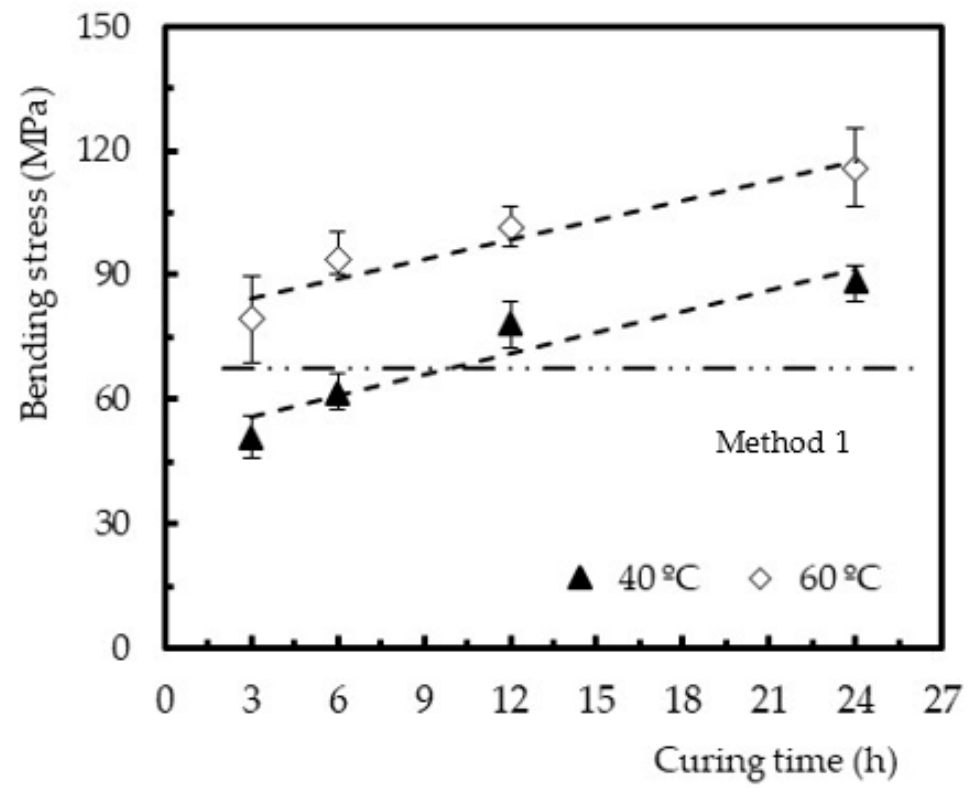

(b)

Figure 7. (a) Effect of the curing parameters on the bending stress and (b) effect of the post-cure on the bending stress.

On the other hand, in the case of post-cures effect, the viscosity induced by the crosslinking at RT makes further reticulation when the temperature is increased during the second stage of the process difficult. This behavior is explained by the diffusion problems of the crosslinking agent within the reticulated structure. Regardless of the curing temperatures, Figure $7 \mathrm{~b}$ confirms what was observed in Figure 4, and a linear increase in bending strength was observed as a function of the exposure time. A higher degree of conversion was achieved for higher exposure times, which, in principle, implies lower molecular mobility $[19,22]$. For example, the bending strength obtained for a post-cure at $40{ }^{\circ} \mathrm{C}$ for $24 \mathrm{~h}$ was $73.9 \%$ higher than the value obtained at $40{ }^{\circ} \mathrm{C}$ for $3 \mathrm{~h}$. At $60^{\circ} \mathrm{C}$ post-cure temperature, the increase was around $46.1 \%$.

Figure 8 shows the post-cure effect on bending stiffness, and a behavior very similar to that obtained for bending strength was observed. 


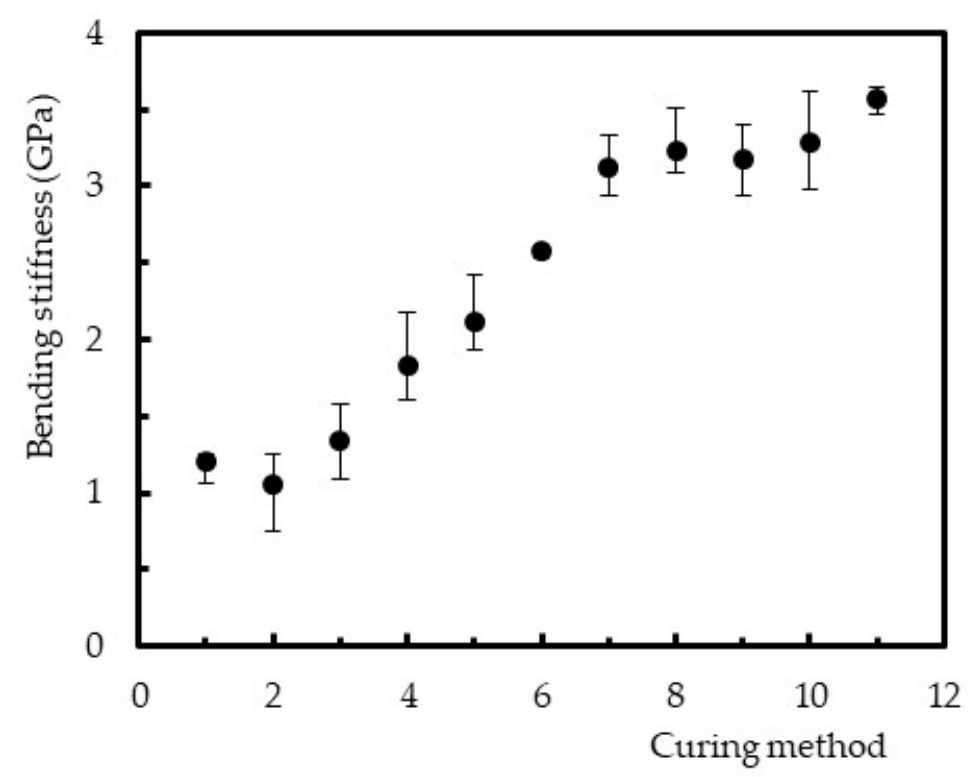

(a)

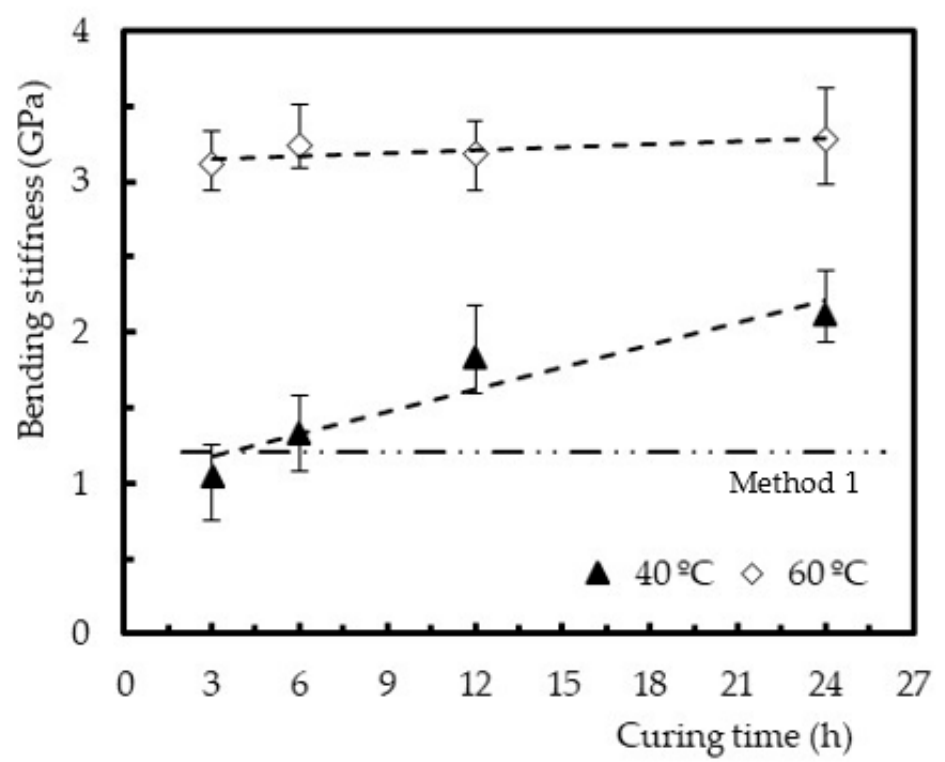

(b)

Figure 8. (a) Effect of the curing parameters on bending stiffness and (b) effect of the post-cure on bending stiffness.

In more detail, from Figure 8a, it is possible to observe that, for methods without post-cures (methods 1,6, and 11), an increase in temperature was responsible for higher bending stiffness values. Bending stiffness was about two times higher for $40^{\circ} \mathrm{C}$ (method 6) and three times higher for $60^{\circ} \mathrm{C}$ (method 11), compared to the value obtained at room temperature. As reported above, and according to Figure 4 and Table 2, the lower molecular mobility due to a higher density of crosslinking explains these improvements $[19,22]$. However, when the post-cure effect was analyzed separately in Figure $8 b$, one more time, a linear increase was observed as a function of the exposure time. Higher exposure times promote a higher degree of conversion of the unsaturated ester bonds, and, consequently, less molecular mobility $[19,22]$. The bending stiffness obtained for a post-cure at $40{ }^{\circ} \mathrm{C}$ for $24 \mathrm{~h}$ was $73.3 \%$ higher than the value obtained at $40^{\circ} \mathrm{C}$ for $3 \mathrm{~h}$, and for the same comparison at $60^{\circ} \mathrm{C}$ this value was only $5.5 \%$ higher. It is noticed that the exposure time was less expressive in this property with increasing temperature. A brief comparison with the study developed by Gudapati et al. [37], carried 
out with a cure of $24 \mathrm{~h}$ at RT followed by $2 \mathrm{~h}$ at $80^{\circ} \mathrm{C}$, evidences a bending modulus similar to the value obtained with method 3 ( $24 \mathrm{~h}$ at RT followed by a post-cure performed at $40^{\circ} \mathrm{C}$ for $6 \mathrm{~h}$ ). In this context, it is noticed the post-cure temperature effect on the crosslinking and, consequently, on the mechanical properties. As reported above, it is the most important factor that influences the extent of cross linking [8]. However, in terms of flexural strength, these authors obtained lower values.

Considering the viscoelastic behavior, Figure 9 presents the stress relaxation curves only for the methods without the post-cure. This figure plots the average bending stress versus time, where $\sigma$ is the bending stress at any given moment of the test, and $\sigma_{0}$ is the initial bending stress. The final bands represent the maximum and minimum values obtained for each condition analyzed.

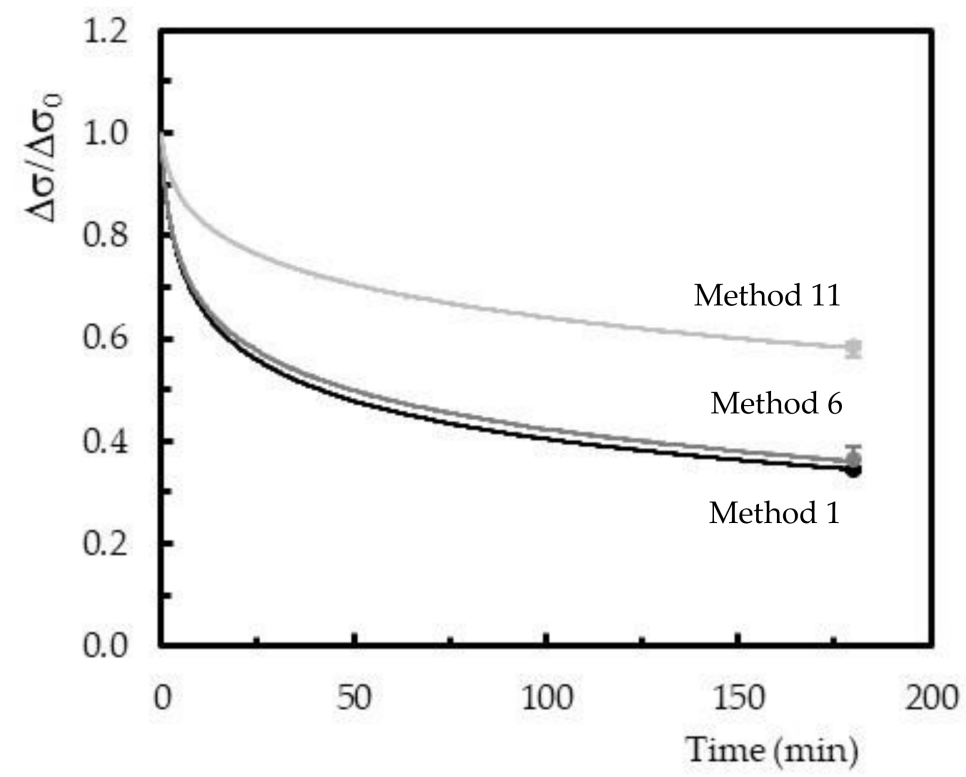

Figure 9. Stress relaxation curves obtained for the specimens 1, 6, and 11 (bending strain correspondent to $51.5 \mathrm{MPa}$ ).

In general, the stress decreased over time to one value expected to be constant, but in the present work, this constant bending stress was not achieved because it focuses on short-term tests. These tests represent an easy, fast, and reliable method to predict long-term behavior [26-28]. Another similarity with the open literature is the existence of an initial stage, in which the stress decreases considerably with the remaining time [38-40]. The duration of this initial stage depends significantly on the material. In the present case, for example, considering the values obtained for method 11, stress decreased around $29.5 \%$ after 50 minutes, but this value reached $17.7 \%$ in the last 130 minutes. Regarding method 6, these values were $50.2 \%$ and $27.5 \%$, while for method 1 they were $52.3 \%$ and $27.9 \%$, respectively. This result was clear evidence that the bending stress was tending to a constant value, as reported above.

The curing process' effect was also analyzed at the level of difference observed between the initial bending stress value and the final one after 3 hours. It was possible to conclude that, for curing at room temperature, the bending stress decreased around $65.6 \%$ concerning the initial value. However, this value was $63.9 \%$ for $40{ }^{\circ} \mathrm{C}$ and $42 \%$ for $60{ }^{\circ} \mathrm{C}$. This decrease is well reported in the open literature, which is based on physical phenomena (molecular rearrangements that require little formation or rupture of primary bonds) and/or chemical phenomena (chain scission, crosslink scission, or crosslink formation) [41-43]. Both were expected in this study, but it is possible to conclude that higher curing temperatures decrease stress relaxation behavior. As reported in the static properties, also the best performance in terms of stress relaxation was obtained for a temperature of $60{ }^{\circ} \mathrm{C}$. The degree of conversion, as shown in Figure 4, was 1.2 times higher than the one observed at $40^{\circ} \mathrm{C}$, and, consequently, this resin system had less molecular mobility. 
The reasons that explain the stress relaxation behavior are the same that support the creep curves shown in Figure 10, where $\varepsilon$ represents the strain value obtained at any instant of the test, and $\varepsilon_{0}$ is the initial instantaneous strain (value obtained immediately after application of the respective load). The final bands represent the maximum and minimum values obtained for each condition analyzed. It is possible to observe that all curves present an instantaneous strain, followed by the primary and secondary creep regimes that characterize the typical creep curves. In this study, the third regime was expected to occur only for higher stress values or longer times. Finally, the strain increased with time; however, this behavior became less pronounced with the increasing of curing temperature. For example, while for control samples (method 1), the initial strain was around 3.2 times higher concerning its initial value, this value decreased to 2.9 times for $40{ }^{\circ} \mathrm{C}$ and to 2 times for $60^{\circ} \mathrm{C}$. In this case, the curing temperature of $60^{\circ} \mathrm{C}$ promoted a decrease of the creep strain, after $180 \mathrm{~mm}$, around $37.5 \%$ concerning the resin cured at room temperature.

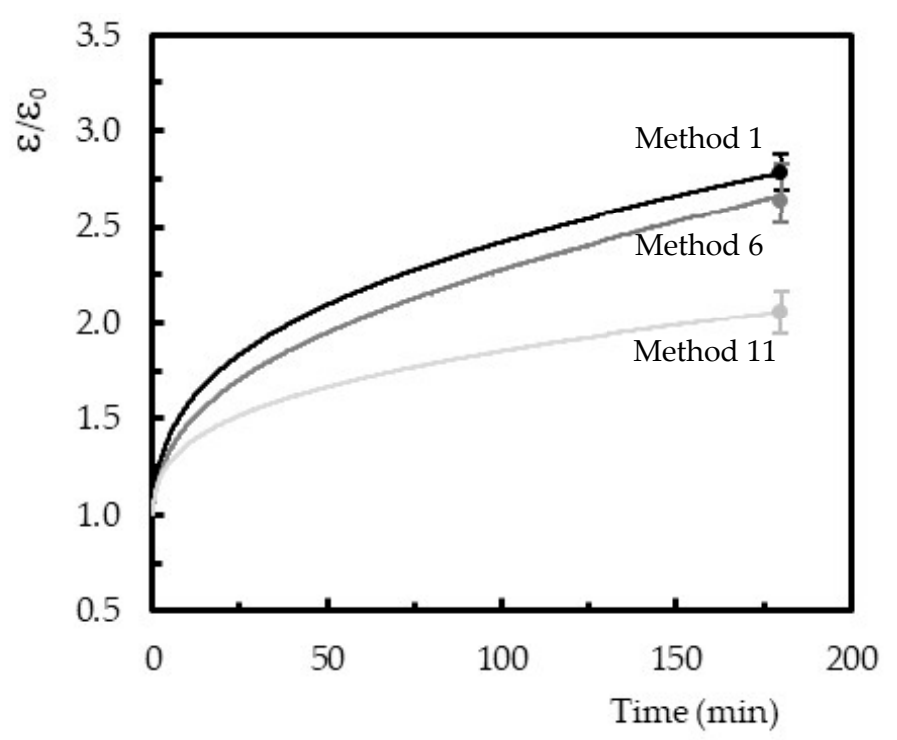

Figure 10. Creep curves obtained for the methods 1,6 , and 11 (bending stress of $20 \mathrm{MPa}$ ).

The creep phenomenon in polymers occurs even at room temperature and for stresses below their ultimate strength due to the molecular motion in the backbone polymer arrangement [44-47]. Therefore, the degree of conversion 1.4 times higher for $40{ }^{\circ} \mathrm{C}$ and 1.6 times for $60^{\circ} \mathrm{C}$, when compared to the value obtained at room temperature, explains the higher crosslinking rate and, consequently, the lower molecular mobility in the resin. In such a context, lower creep strain values are expected/obtained.

Finally, the ability to model the viscoelastic behavior of polymer-based materials is determined to predict their long-term structural behavior. In terms of stress relaxation, for example, literature reports complex models to the detriment of those based on spring-dashpot systems, because the data are not fitted by a linear function. Therefore, the Kohlrausch-Williams-Watts (KWW) function, an empirical "stretched exponential" function, is suggested by the open literature as an appropriate methodology to model the stress relaxation $[27,28,39,40,48,49]$. According with this model, the relaxation function $\emptyset$ as a function of time is given by Equation (4):

$$
\varnothing=\frac{\sigma(t)}{\sigma_{0}}=e^{-\left(\frac{t}{\tau}\right)^{\beta}}
$$

where $\sigma(t)$ and $\sigma_{0}$ are the stress at time $t$ and at $t=0$, respectively, $\beta$ a fractional power exponent (known as non-exponential factor), and $\tau$ the KWW relaxation time.

Figure 11 compares the experimental results against the theoretical ones obtained with the KWW model for samples cured by Method 1. These curves are representative of all conditions and, apparently, the Kohlrausch-Williams-Watts (KWW) function fits the data successfully. Table 3 reports 
all parameters of the KWW model and its accuracy, where the errors observed between the average experimental curve and the KWW prediction were less than $8.9 \%$ (in absolute value) after $3 \mathrm{~h}$ of testing. Therefore, it is possible to conclude that the model fits to the data successfully.

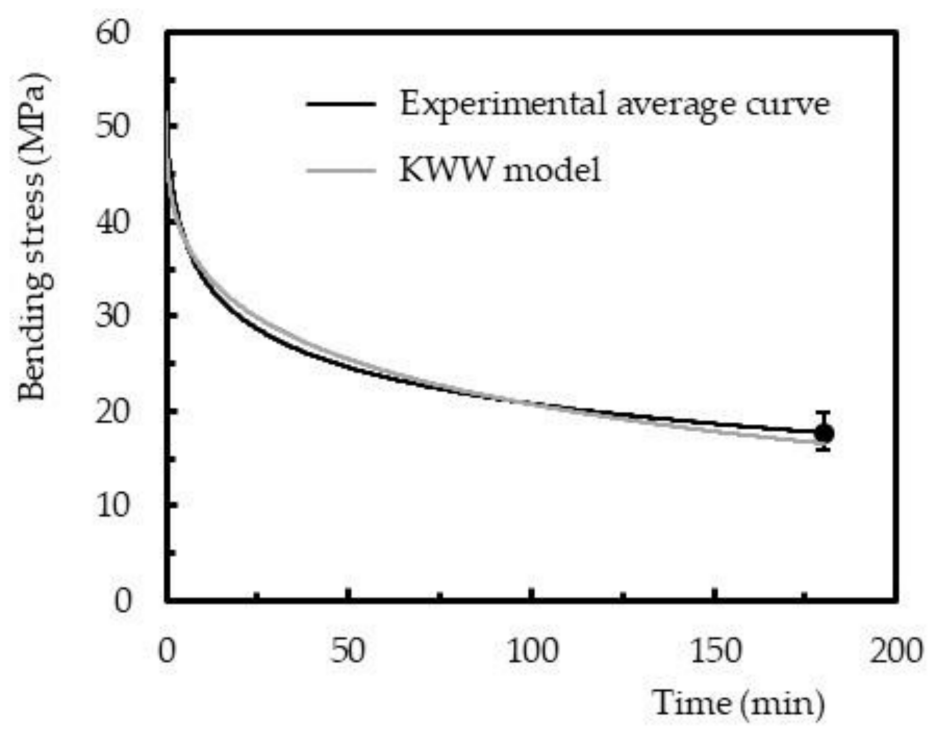

Figure 11. Comparison between the experimental average curve and theoretical curve obtained with the Kohlrausch-Williams-Watts (KWW) model for samples cured by method 1 (bending strain correspondent to $51.5 \mathrm{MPa}$ ).

Table 3. Parameters of the KWW model for stress relaxation.

\begin{tabular}{cccccc}
\hline \multirow{2}{*}{ Curing Method } & \multirow{3}{*}{$\boldsymbol{\tau}$} & $\boldsymbol{\tau}$ & \multicolumn{3}{c}{ Bending Stress after 3 h (MPa) } \\
\cline { 4 - 6 } & & & Experimental Value & KWW Value & Error (\%) \\
\hline 1 & 0.372 & $1.29 \times 10^{2}$ & 17.7 & 16.6 & 6.2 \\
6 & 0.393 & $2.83 \times 10^{2}$ & 19.4 & 21.3 & 8.9 \\
11 & 0.409 & $7.12 \times 10^{2}$ & 29.9 & 29.1 & 2.7 \\
\hline
\end{tabular}

Regarding the creep behavior, the Findley power law model is one of the most widely used to describe this phenomenon in composite materials and has been recommended, inclusively, by the ASCE Structural Plastics Design Manual to analyze and design the long-term strength [50]. The Findley's power law is given by Equation (5):

$$
\varepsilon(t)=\varepsilon_{0}+A t^{n}
$$

where $\varepsilon(t)$ is the creep displacement at time $t, \varepsilon_{0}$ is the instantaneous elastic displacement or time-independent, $A$ is the amplitude of transient creep (time-dependent), and $n$ is a constant independent of the stress and generally less than one [51]. Several studies can be found in the open literature, where the Findley's power law was also applied to short-term creep data [27,28,51-53].

Therefore, similar to the previous figure, Figure 12 compares the experimental results against the theoretical ones obtained with the Findley power law model for samples cured by method 1 . These curves are representative of all the conditions studied, and it is noticed that the Findley model fits the data successfully. Table 4 reports all parameters of the Findley power law model and its accuracy after $3 \mathrm{~h}$ of testing. The maximum error observed between the average experimental curves and the predicted ones was less than $7.1 \%$, for all conditions studied, which confirms that the model fits the experimental data successfully. 


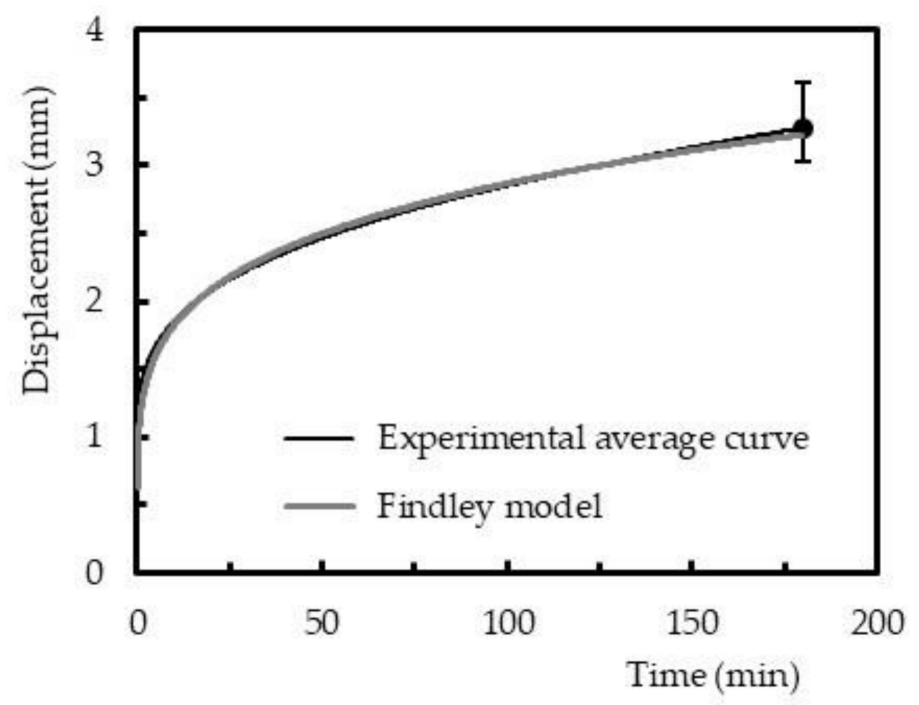

Figure 12. Comparison between experimental average curve and theoretical curve obtained with the Findley power law model for samples cured by method 1 (bending stress of $20 \mathrm{MPa}$ ).

Table 4. Parameters of the Findley power law model for creep.

\begin{tabular}{ccccccc}
\hline \multirow{2}{*}{ Curing Method } & \multirow{2}{*}{$\varepsilon_{\mathbf{0}}$} & \multirow{A}{*}{$\boldsymbol{*}$} & $\boldsymbol{n}$ & \multicolumn{3}{c}{ Displacement after 3 h (MPa) } \\
\cline { 5 - 7 } & & & & Experimental Value & Findley Value & Error (\%) \\
\hline 1 & 0.229 & 0.397 & 0.218 & 3.3 & 3.2 & 3.0 \\
6 & 0.231 & 0.378 & 0.199 & 2.5 & 2.6 & 3.8 \\
11 & 0.177 & 0.250 & 0.166 & 1.4 & 1.3 & 7.1 \\
\hline
\end{tabular}

\section{Conclusions}

The main goal of this study was to analyze the effect of the curing parameters on the mechanical properties of a polyester resin usually used in surfboards. For this purpose, the curing temperature was lower than the normally used with this type of resins, for other applications, in order to obtain lower percentages of curing and evaluate their influence on the mechanical properties. Moreover, the use of lower temperatures also has a beneficial impact both to the economic and environmental aspects. Three-point bending tests were performed to assess the bending properties and both stress relaxation and creep behavior.

The polymer if cured at room temperature, even when followed by short times of post-curing at $40{ }^{\circ} \mathrm{C}$, presents unreacted macromolecules according to the DSC characterization. The higher percentages of crosslinking were obtained when the curing process was made at $60^{\circ} \mathrm{C}$ for $24 \mathrm{~h}$.

In terms of static properties, it was also possible to conclude that using higher curing temperatures, without post-curing, is preferable to the approach that involves curing followed by post-curing, because the exposure time at room temperature induces a percentage of conversion of double bonds that difficult further crosslinking in the second process step (post-cure). Therefore, the maximum bending strength and modulus were obtained at $60^{\circ} \mathrm{C}$ for $24 \mathrm{~h}$. Finally, it was also noticed that, when a post-cure was applied, these properties increased linearly with the exposure time due to a higher degree of conversion achieved.

Finally, the viscoelastic behavior was evaluated, and both stress relaxation and creep strain presented the lowest values for samples cured at $60^{\circ} \mathrm{C}$. The degree of conversion was higher for $60^{\circ} \mathrm{C}$, and, consequently, this resin system had less molecular mobility due to its higher crosslinking. The Kohlrausch-Williams-Watts (KWW) equation and the Findley power law model were used to predict the viscoelastic behavior, and good accuracy was obtained between the experimental results and those predicted by the proposed models. 
Author Contributions: P.N.B.R. conceived and designed the study, P.S., J.M.P. and S.V. conducted the experiments related with mechanical characterization, A.P.P. conducted the chemical experiments. M.P.S., P.N.B.R. and A.P.P. analyzed the results. M.P.S. and A.P.P. wrote the paper. All authors read and approved the final manuscript.

Funding: This work was supported by the project Centro-01-0145-FEDER-000017_EMaDeS—Energy, Materials and Sustainable Development, co-financed by the Portugal 2020 Program (PT 2020), within the Regional Operational Program of the Center (CENTRO 2020) and the European Union through the European Regional Development Fund (ERDF).

Acknowledgments: This work was partially supported by the project UIDB/EMS/00285/2020 from Fundação para a Ciência e a Tecnologia, Portugal.

Conflicts of Interest: The authors declare no conflict of interest.

\section{References}

1. Devi, L.U.; Bhagawan, S.S.; Thomas, S. Mechanical properties of pineapple leaf fiber-reinforced polyester composites. J. Appl. Polym. Sci. 1997, 64, 1739-1748. [CrossRef]

2. Vilas, J.L.; Laza, J.M.; Garay, M.T. Unsaturated polyester resins cure: Kinetic, rheologic, and mechanical dynamical analysis. II. The glass transition in the mechanical dynamical spectrum of polyester networks. J. Polym. Sci. B Polym. Phys. 2001, 39, 146-152. [CrossRef]

3. Mohd Nurazzi, N.; Khalina, A.; Sapuan, S.M.; Dayang Laila, A.M.; Rahmah, M. Curing behaviour of unsaturated polyester resin and interfacial shear stress of sugar palm fibre. J. Mech. Eng. Sci. 2017, 11, 2650-2664. [CrossRef]

4. de la Caba, K.; Guerrero, P.; Eceiza, A.; Mondragon, I. Kinetic and rheological studies of an unsaturated polyester cured with different catalyst amounts. Polymer 1996, 37, 275-280. [CrossRef]

5. Huang, Y.J.; Leu, J.S. Curing of unsaturated polyester resins. Effects of temperature and initiator: 1. Low temperature reactions. Polymer 1993, 34, 295-304. [CrossRef]

6. Crawford, R.J. Plastics Engieneering, 2nd ed.; Pergamon Press: New York, NY, USA, 1987.

7. Stark, W. Investigation of the curing behaviour of carbon fibre epoxy prepreg by Dynamic Mechanical Analysis DMA. Polym. Test. 2013, 32, 231-239. [CrossRef]

8. Aruniit, A.; Kers, J.; Krumme, A.; Poltimäe, T.; Tall, K. Preliminary study of the influence of post curing parameters to the particle reinforced composite's mechanical and physical properties. Mater. Sci. 2012, 18, 256-261. [CrossRef]

9. Ramis, X.; Salla, J.M. Theoretical and experimental conversion in the curing of unsaturated polyester resins with styrene as a crosslinking agent. J. Appl. Polym. Sci. 1992, 45, 227-236. [CrossRef]

10. Salla, J.M.; Ramis, X. Comparative study of the cure kinetics of an unsaturated polyester resin using different procedures. Polym. Eng. Sci. 1996, 36, 835-851. [CrossRef]

11. Ramis, X.; Salla, J.M. Effect of the initiator content and temperature on the curing of an unsaturated polyester resin. J. Polym. Sci. B Polym. Phys. 1999, 37, 751-768. [CrossRef]

12. de la Caba, K.; Guerrero, P.; Mondragon, I.; Kenny, J.M. Comparative study by DSC and FTIR techniques of an unsaturated polyester resin cured at different temperatures. Polym. Int. 1998, 45, 333-338. [CrossRef]

13. Xu, X.; Zhou, Q.; Song, N.; Ni, Q.; Ni, L. Kinetic analysis of isothermal curing of unsaturated polyester resin catalyzed with tert-butyl peroxybenzoate and cobalt octoate by differential scanning calorimetry. J. Therm. Anal. Calorim. 2017, 129, 843-850. [CrossRef]

14. Worzakowska, M. The influence of tertiary aromatic amines on the BPO initiated cure of unsaturated epoxy polyesters with styrene studied by non-isothermal DSC. J. Therm. Anal. Calorim. 2011, 105, 987-994. [CrossRef]

15. Poorabdollah, M.; Beheshty, M.H.; Vafayan, M. Kinetic modeling of nanoclay-reinforced unsaturated polyester resin. Polym. Compos. 2011, 32, 1265-1273. [CrossRef]

16. Martin, J.L. Kinetic analysis of two DSC peaks in the curing of an unsaturated polyester resin catalyzed with methylethylketone peroxide and cobalt octoate. Polym. Eng. Sci. 2007, 47, 62-70. [CrossRef]

17. Senthilkumar, K.; Siva, I.; Chandrasekar, M.; Rajini, N.; Kalusuraman, G.; Karthikeyan, S.; Vishnuteja, B.; Mallikarjuna, B. Influence of curing temperature on the mechanical and free vibration properties of sisal fiber reinforced polyester composites. In AIP Conference Proceedings, Proceedings of The 3rd International Conference on Automotive Innovation and Green Energy Vehicle, Kuantan, Malaysia, 25-26 July 2018; AIP Publishing: New York, NY, USA, 2018; p. 020066. 
18. Kumar, D.S.; Shukla, M.J.; Mahato, K.K.; Rathore, D.K.; Prusty, R.K.; Ray, B.C. Effect of post-curing on thermal and mechanical behavior of GFRP composites. In IOP Conference Series: Materials Science and Engineering, Proceedings of the 4th National Conference on Processing and Characterization of Materials, Rourkela, India, 5-6 December 2014; IOP Publishing Ltd.: Bristol, UK, 2015; Volume 75, p. 012012.

19. Campana, C.; Leger, R.; Sonnier, R.; Ferry, L.; Ienny, P. Effect of post curing temperature on mechanical properties of a flax fiber reinforced epoxy composite. Compos. Part A Appl. Sci. Manuf. 2018, 107, 171-179. [CrossRef]

20. Nicolais, L.; Landel, R.F.; Giordano-Orsini, P. The Glass Transition Temperature of Poly(phenylene oxide): Annealing and Filler Effects. Polym. J. 1975, 7, 259-263. [CrossRef]

21. Crowson, R.J.; Arridge, R.G.C. The elastic properties in bulk and shear of a glass bead-reinforced epoxy resin composite. J. Mater. Sci. 1977, 12, 2154-2164. [CrossRef]

22. Elleuch, R.; Zidi, M.; Bradai, C. Effects of post-cure on the mechanical properties of woven glass-polyester composite by macro and micro-mechanical methods. Sci. Eng. Compos. Mater. 1999, 8, 25-34. [CrossRef]

23. ASTM. D7264/D7264M—07 Standard Test Method for Flexural Properties of Polymer Matrix Composite Materials; ASTM: West Conshohocken, PA, USA, 2015.

24. ASTM. D6048 - 07(2018) Standard Practice for Stress Relaxation Testing of Raw Rubber, Unvulcanized Rubber Compounds, and Thermoplastic Elastomers; ASTM: West Conshohocken, PA, USA, 2018.

25. ASTM. D7337/D7337M-12(2019) Standard Test Method for Tensile Creep Rupture of Fiber Reinforced Polymer Matrix Composite Bars; ASTM: West Conshohocken, PA, USA, 2019.

26. Lim, S.D.; Rhee, J.M.; Nah, C.; Lee, S.H.; Lyu, M.Y. Predicting the long-term creep behavior of plastics using the short-term creep test. In International Polymer Processing; Carl Hanser Verlag: Munich, Germany, 2004; Volume 19, pp. 313-319.

27. Reis, P.N.B.; Silva, M.P.; Santos, P.; Parente, J.M.; Bezazi, A. Viscoelastic behaviour of composites with epoxy matrix filled by cork powder. Compos. Struct. 2020, 234, 111669. [CrossRef]

28. Reis, P.N.B.; Silva, M.P.; Santos, P.; Parente, J.M.; Valvez, S.; Bezazi, A. Mechanical performance of an optimized cork agglomerate core-glass fibre sandwich panel. Compos. Struct. 2020, 245, 112375. [CrossRef]

29. Yang, Y.S.; Lee, L.J. Polymerization of Polyurethane-Polyester Interpenetrating Polymer Network (IPN). Macromolecules 1987, 20, 1490-1495. [CrossRef]

30. Yang, Y.; Lee, L.J. Rheokinetic Studies of Unsaturated Polyester Resins; Dekker: New York, NY, USA, 1988.

31. Yang, Y.S.; Lee, L.J. Comparison of thermal and infrared spectroscopic analyses in the formation of polyurethane, unsaturated polyester, and their blends. J. Appl. Polym. Sci. 1988, 36, 1325-1342. [CrossRef]

32. Rahmat, A.R.; Day, R.J. Curing Characteristics of Unsaturated Polyester/aramid Reinforced Composite: Microwave vs. Thermal Energy. J. Teknol. 2003, 39, 83-96. [CrossRef]

33. Ma, S.C.; Lin, H.L.; Yu, T.L. Glass Transition Temperature, Free Volume, and Curing Kinetics of Unsaturated Polyester. Polym. J. 1993, 25, 897-907. [CrossRef]

34. Lucas, J.C.; Borrajo, J.; Williams, R.J.J. Cure of unsaturated polyester resins: 1 . Heat of copolymerization and glass transition temperature. Polymer 1993, 34, 3216-3219. [CrossRef]

35. Yu, T. Glass Transition Temperature Profile of the Curing Reaction of Unsaturated Polyester Resin. Polym. J. 1996, 28, 965-969. [CrossRef]

36. Delaite, C.; Bistac, S.; Dreyer, E.; Schuller, A.-S. Influence of glass transition temperature of crosslinked unsaturated polyester resin/styrene formulations on the final conversion after an isothermal curing at $100{ }^{\circ} \mathrm{C}$. Polym. Adv. Technol. 2020, 1-7. [CrossRef]

37. Gudapati, S.P.K.; Krishna, C.V.; Prasad, A.V.R. Effect of nano clay on tensile and flexural properties of vakka fiber polyester composites. Mater. Today Proc. 2019, 18, 2032-2035. [CrossRef]

38. Ferreira, J.A.M.; Costa, J.D.M.; Reis, P.N.B. Static and fatigue behaviour of glass-fibre-reinforced polypropylene composites. Theor. Appl. Fract. Mec. 1999, 31, 67-74. [CrossRef]

39. Reis, P.N.B.; Gorbatikh, L.; Ivens, J.; Lomov, S.V. Strain-rate sensitivity and stress relaxation of hybrid self-reinforced polypropylene composites under bending loads. Compos. Struct. 2019, 209, 802-810. [CrossRef]

40. Reis, P.N.B.; Silva, M.P.; Santos, P. Stress Relaxation in Delaminated Carbon/Epoxy Composites. Fibers Polym. 2019, 20, 1284-1289. [CrossRef]

41. Varghese, S.; Kuriakose, B.; Thomas, S. Stress relaxation in short sisal-fiber-reinforced natural rubber composites. J. Appl. Polym. Sci. 1994, 53, 1051-1060. [CrossRef] 
42. George, J.; Sreekala, M.S.; Thomas, S.; Bhagawan, S.S.; Neelakantan, N.R. Stress Relaxation Behavior of Short Pineapple Fiber Reinforced Polyethylene Composites. J. Reinf. Plast. Comp. 1998, 17, 651-672. [CrossRef]

43. Sreekala, M.S.; Kumaran, M.G.; Joseph, R.; Thomas, S. Stress-relaxation behaviour in composites based on short oil-palm fibres and phenol formaldehyde resin. Compos. Sci. Technol. 2001, 61, 1175-1188. [CrossRef]

44. Park, B.-D.; Balatinecz, J.J. Short term flexural creep behavior of wood-fiber/polypropylene composites. Polym. Compos. 1998, 19, 377-382. [CrossRef]

45. Houshyar, S.; Shanks, R.A.; Hodzic, A. Tensile creep behaviour of polypropylene fibre reinforced polypropylene composites. Polym. Test. 2005, 24, 257-264. [CrossRef]

46. Koubaa, A.; Perré, P.; Cloutier, A. Creep behaviour of HDPE/wood particle composites. Int. J. Microstruct. Mater. Prop. 2013, 8, 225-238.

47. Wang, W.-H.; Huang, H.-B.; Du, H.-H.; Wang, H. Effects of fiber size on short-term creep behavior of wood fiber/HDPE composites. Polym. Eng. Sci. 2015, 55, 693-700. [CrossRef]

48. Fancey, K.S. A mechanical model for creep, recovery and stress relaxation in polymeric materials. J. Mater. Sci. 2005, 40, 4827-4831. [CrossRef]

49. Vaidyanathan, T.K.; Vaidyanathan, J. Validity of predictive models of stress relaxation in selected dental polymers. Dent. Mater. 2015, 31, 799-806. [CrossRef] [PubMed]

50. Scott, D.W.; Lai, J.S.; Zureick, A.H. Creep behavior of fiber-reinforced polymeric composites: A review of the technical literature. J. Reinf. Plast. Compos. 1995, 14, 588-617. [CrossRef]

51. Almeida, J.H.S.; Ornaghi, H.L.; Lorandi, N.P.; Bregolin, B.P.; Amico, S.C. Creep and interfacial behavior of carbon fiber reinforced epoxy filament wound laminates. Polym. Compos. 2018, 39, E2199-E2206. [CrossRef]

52. Georgiopoulos, P.; Kontou, E.; Christopoulos, A. Short-term creep behavior of a biodegradable polymer reinforced with wood-fibers. Compos. Part B Eng. 2015, 80, 134-144. [CrossRef]

53. Gupta, V.B.; Lahiri, J. Non linear viscoelastic behavior of polypropylene and glass reinforced polypropylene in creep. J. Compos. Mater. 1980, 14, 286-296. [CrossRef]

(C) 2020 by the authors. Licensee MDPI, Basel, Switzerland. This article is an open access article distributed under the terms and conditions of the Creative Commons Attribution (CC BY) license (http://creativecommons.org/licenses/by/4.0/). 